\title{
PRECURSORS TO RADAR - THE WATSON-WATT MEMORANDUM AND THE DAVENTRY EXPERIMENT
}

\author{
B. A. AUSTIN \\ Department of Electrical Engineering and Electronics, University of Liverpool, \\ Liverpool.E-mail:ee104@liverpool.ac.uk
}

\begin{abstract}
In this paper we examine the famous unpublished memorandum of 1935 in which R. A. Watson-Watt proposed the principles of radar. Starting from the numerical results he quoted, we show how he arrived at his conclusions using nothing more than simple calculations. The origins of an important modern technology are to be found in a combination of prescience and fundamental engineering skills.
\end{abstract}

KEYWORDS antenna theory; first-principles; radar

\section{INTRODUCTION}

With the approach of the millenium and a century or more of electrical science now behind us it is probably a most appropriate time to look back in order to see how this most technological of periods in the existence of mankind actually evolved. While much was due to the endeavours of scientists and engineers working solely for the good of their fellow human beings some of the greatest developments came about in order to thwart the designs of evil men and were, in fact, made during wartime. One of these engineering feats of the century, and arguably the one that saved the free world, was radar.

On Good Friday 1939 the 'Chain Home' radar system became operational for the first time along the south and east coasts of England ${ }^{1}$. These 20 stations were the result of intense scientific and engineering activity during the preceding four years since R. A. Watson-Watt had presented his remarkable memorandum on the feasibility of detecting aircraft by means of scattered or reflected electromagnetic radiation.

Since then, the technology of radar has advanced in huge strides and its use is now very much taken for granted in civil and military aviation, maritime navigation and in space. In addition, there are now a number of more esoteric applications such as ground-probing radar used for the location of buried objects and artefacts of various types. However, the evolution of this remarkable means of remotely sensing the environment by electromagnetic waves owes its development, as a complete system, to a combination of circumstances dominated by the threat of war and to the prescience of one man with a remarkable grasp of the techniques and applications of radio. That man was Robert Alexander Watson-Watt, then Superintendent of the Radio Research Station at Slough in Berkshire. 
This story is worth re-telling as we move into the next millenium because it is not only a glorious example of science and engineering at their very best but it contains within it a number of numerical results that can be obtained after making no more than calculations 'on the back of an envelope' and that is really the essence of good engineering. It is essentially the skill that sets apart the engineer from those who bear the name but are mere practitioners of a trade.

\section{THE BACKGROUND}

To appreciate fully the magnitude of the problem that Watson-Watt confronted early in 1935, it is important to review briefly the state of the world, and Britain in particular, at that time. Adolf Hitler's grand design that would, he believed, lead to Germany's ultimate domination of the world was underpinned by the development of a massive military machine and particularly of an air force, the Luftwaffe, that would pulverise any opposing force and destroy the industrial infrastructure of those who dared stand in his way. By 1935 the Luftwaffe numbered well in excess of a thousand modern aircraft with the production of more increasing dramatically. By contrast, the Royal Air Force was operating with vintage machines that bore much more resemblance to those that had seen service in the previous war. The situation was therefore perilous and there were those who saw in this only the gravest of consequences for Britain. Fortunately, there were amongst them scientific visionaries who believed that methods could be devised to defeat this threat, even though numerical superiority of aircraft was but a distant dream.

In January 1935 the first meeting of the recently established Committee for the Scientific Survey of Air Defence took place in London under the chairmanship of Henry Tizard. Its members were A. V. Hill, a physiologist and Nobel Laureate, Patrick Blackett, then a young professor of physics of considerable intellectual potential, H. E. Wimperis and A. P. Rowe, the latter two from the Air Ministry; all were to become key players in the story of radar or RDF, as it was then known ${ }^{2}$.

But the way radar acutally was conceived in Britain had more to do with a 'death ray' than with methods of aircraft detection since, as we have seen, the overwhelming superiority of the force ranged against them suggested that desperate measures needed to be adopted to repulse the invading air armada, or at least to incapacitate its pilots. The inclusion of Hill, a physiologist, on this committee certainly suggests that the pilots were the target.

At this point Watson-Watt was brought in. He was asked to comment on the feasibility of producing an intense amount of energy sufficient either to immobilise an aircraft from the ground, or possibly its pilot by raising his body temperature by at least $2^{\circ} \mathrm{C}$. This request led Watson-Watt to write two memoranda that must rank amongst the most important scientific documents ever produced that were never written for publication.

\section{THE 'DEATH RAY' BECOMES RADAR}

The first of Watson-Watt's two memoranda was prepared in mid-January 1935 and was submitted to the Air Ministry soon afterwards. In it he dismissed the 
possibility of a death ray capable of inconveniencing the pilot of even a lowflying aircraft. To bring about an increase in the pilot's body temperature by the suggested $2^{\circ}$, using radio waves, would require a transmitter capable of delivering about $5 \mathrm{GW}$ to its dipole antenna. Even allowing for the use of elaborate antenna arrays to focus the energy, and so decrease the power requirement somewhat, this still implied that power levels of hundreds of kilowatts at wavelengths of just a few metres would be needed. Such technology was well beyond the reach of any nation at that time. The idea was even less practicable when it was appreciated that the operators of the death-ray apparatus would be at considerably more risk than their intended victims, and the system would probably be so massive as to be capable only of generating a beam fixed in one direction and thus easily avoided, once detected!

However, the close examination of such fanciful ideas produced an entirely unexpected result: the aircraft itself would re-radiate sufficient of the energy that was incident upon it to make its detection and ultimately its tracking quite within the technical capabilities of any of the advanced nations of that time. The credit for performing the calculations that produced this remarkable finding goes to A. F. Wilkins, one of Watson-Watt's assistants at Slough.

To estimate the amount of power that would be re-radiated by a metalskinned bomber of the type then beginning to roll off the production lines in Germany, Arnold Wilkins invoked some elementary principles of physical optics that were equally applicable to the analysis of simple antenna arrays. The simplicity of the method and the significance of the results it produced caused Watson-Watt initially to have some doubts as to their accuracy and, as he conceded, 'I am still nervous as to whether we have not got a factor of ten wrong, but even that would not be fatal ${ }^{3}$. We can probably assume that the calculations proceeded along the lines set out below.

Since a typical night-bomber of the time had a wingspan of the order of $25 \mathrm{~m}$ it could be expected to act as a resonant, dipole-like, antenna when exposed to electromagnetic energy from a transmitter operating at a wavelength of twice that dimension. Being of highly conducting material, the wings would then have induced in them a current that, in turn, should produce a field that would re-radiate and so disclose the presence of the aircraft to a suitably tuned receiver some distance away. To determine the magnitudes of these effects Watson-Watt and Wilkins assumed that such an aircraft was flying at an altitude of $6 \mathrm{~km}$ and at a horizontal distance of $6 \mathrm{~km}$ from a ground-based transmitter that was radiating energy at $6 \mathrm{MHz}$ - the required $50 \mathrm{~m}$ wavelength. Figure 1 shows this diagrammatically.

\section{ANALYSIS}

A horizontal dipole antenna at a height $h$ above a perfectly conducting ground plane produces a radiated field $E_{\mathrm{T}}=E_{\mathrm{d}}+E_{\mathrm{r}}$ where $E_{\mathrm{d}}$ is the direct ray between antenna and target and $E_{\mathrm{r}}$ is the reflected component from the ground and both, of course, are phasors. By invoking image theory and the appropriate boundary conditions the ground can be replaced by the image of the antenna 


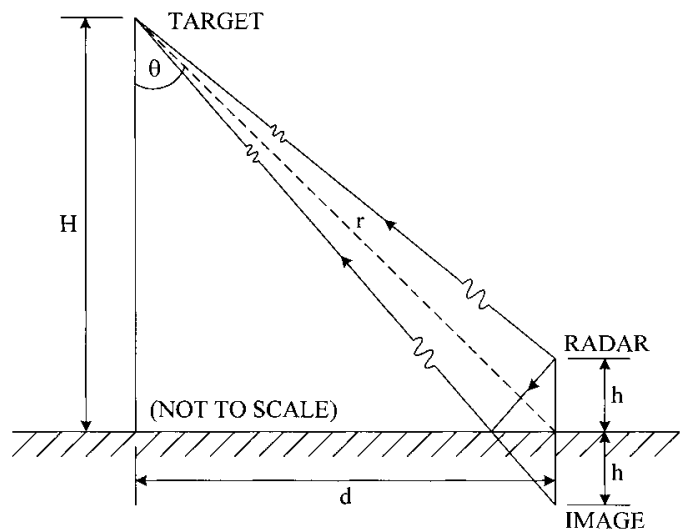

FIG. 1 Diagrammatic view of the ground-based radar antenna and an airborne target.

at a distance $h$ below the ground plane, as shown in Fig. 1. Thus we get

$$
E_{\mathrm{T}}=E_{\mathrm{d}}\left(1+k \mathrm{e}^{j \psi}\right)
$$

where $k$ is the ratio of the currents in the antenna and its image and $\psi$ is the phase difference between the fields radiated by the antenna and its image. Thus, from the geometry, we can show that

$$
\psi=2 \beta h \cos \phi-\pi,
$$

where $\beta=2 \pi / \lambda$ and $2 h$ is the distance between the antenna and its image, while $\pi$ radians represents the $180^{\circ}$ phase-shift between them for this horizontal antenna orientation, thereby satisfying the air-ground boundary condition. On the assumption of a perfectly conducting ground, $k=1$, and so the magnitude of the total field strength at the target becomes

$$
\left|E_{\mathrm{T}}\right|=E_{\mathrm{d}} \sqrt{(1+k \cos \psi)^{2}+k^{2} \sin ^{2} \psi}=2 E_{\mathrm{d}} \cos \frac{\psi}{2}
$$

which reaches its maximum value when $\psi=0$; the so-called 'principal maximum' ${ }^{4}$ of the array, and the total field intensity at the target is doubled. Therefore, on substituting the values of $6 \mathrm{~km}$ for the horizontal distance, $d$, and altitude, $H$, of the target in Fig. 1 , as was postulated, gives $\phi=45^{\circ}$ and then, after solving equation (2) with $\psi=0$, we find that the antenna should be elevated about $18 \mathrm{~m}$ above the ground to produce its maximum signal at the altitude of the target. This was indeed the height that Watson-Watt and Wilkins suggested.

They then proposed that the radar transmitter might use a $\lambda / 2$ dipole antenna at this height of $18 \mathrm{~m}$, from which it would then be possible to determine the field intensity at some point, $r$, if the antenna carried a current $I_{\mathrm{m}}$ at its feedpoint. To obtain this result we use the well-known expression for the far- 
field in the azimuthal plane of a $\lambda / 2$ dipole $^{5}$

$$
E=\frac{60 I_{\mathrm{m}}}{r}\left[\frac{\cos \left(\frac{\pi}{2} \cos \theta\right)}{\sin \theta}\right]
$$

Here, the antenna is aligned for optimal sighting of the target, i.e. $\theta=90^{\circ}$, and so the maximum electric field component is simply $E_{\max }=\left(60 I_{\mathrm{m}} / r\right)$. But the effect of the image must also be included and this doubles the field intensity as was shown above. The actual range to the target from the transmitting antenna is the slant range which, for the simple geometrical case that WatsonWatt chose, is given by

$$
r=\sqrt{d^{2}+H^{2}}=\sqrt{72}=8.5 \mathrm{~km}
$$

The resulting field strength at the target, per ampere of current in the transmitting antenna, follows directly as

$$
E_{\mathrm{T}}=\frac{120}{8.5 \times 10^{3}}=14.1 \mathrm{mV} \mathrm{m}^{-1}
$$

This is the value that Watson-Watt quoted in his memorandum.

We now set out to calculate the amount of current, $I_{\mathrm{w}}$, that this field would induce in the wings of the target aircraft if they happened to be parallel to the incident electric field. To perform this calculation we assume, as Watson-Watt did, that 'a typical night-bomber is a metal-winged craft, well bonded throughout, with a span of the order of 25 metres $^{6}$. Such an assumption will ensure that any losses would, at least, be very small compared with the radiation resistance $\left(R_{\mathrm{rad}}=73 \Omega\right)$ if the wing is considered to be a $\lambda / 2$ antenna. Then, by invoking the reciprocity that exists between transmitting and receiving antennas the power coupled into the aircraft's wing, $P_{\mathrm{r}}$, can be determined by using the facts that $P_{\mathrm{r}}=I_{\mathrm{w}}^{2} R_{\mathrm{rad}}=S A_{\mathrm{e}}$, where $S=\left(E_{\mathrm{T}}^{2} / 120 \pi\right)$ is the power flux density of the electric field, $E_{\mathrm{T}}$, in free space with intrinsic impedance of $377 \Omega \approx 120 \pi \Omega$, and $A_{\mathrm{e}}=\left(G \lambda^{2} / 4 \pi\right)$ is the effective aperture of an antenna of gain $G$. Hence, on solving for the current, we obtain

$$
I_{\mathrm{w}}=\sqrt{\frac{E_{\mathrm{T}}^{2} \lambda^{2} G}{480 \pi^{2} R_{\mathrm{rad}}}}
$$

Substituting the appropriate values of $E_{\mathrm{T}}=14.1 \mathrm{~mA} / \mathrm{A}, \lambda=50 \mathrm{~m}$ and $R_{\mathrm{rad}}=$ $73 \Omega$ with $G=1.64$ (the gain of a $\lambda / 2$ dipole) into (5), the current induced in the wings of the aircraft is found to be $1.54 \mathrm{~mA}$ per ampere of that flowing in the transmitting antenna on the ground. Once again this agrees with the value quoted by Watson-Watt.

The crucial calculation, though, was the next one, for it would determine whether the target re-radiated sufficient energy to be detectable on the ground. By assuming that there were no losses within the wing, all the power received 
would be re-radiated, leading to a power flux density at the receiving antenna of $S=\left(G P_{\mathrm{r}} / 2 \pi r^{2}\right)$, since the receiving antenna is in a so-called half-space made up of the earth below, assumed perfectly conducting, and free space above. Now the received electric field is $E_{\mathrm{r}}=\sqrt{120 \pi S}$ from which it follows that

$$
E_{\mathrm{r}}=\frac{\sqrt{60 G I^{2} R_{\mathrm{rad}}}}{r}
$$

On substituting for the current, radiation resistance and slant range we find that the electric field strength at the receiving antenna is $15.4 \mu \mathrm{V} \mathrm{m}^{-1}$ for every ampere of current in the transmitting antenna. (Watson-Watt actually quoted 'about $20 \mu \mathrm{V} \mathrm{m}^{-1}$, — the field strength on the ground beneath the target but the value calculated here is the field strength at the receiver.) Now, as Watson-Watt informed the Air Ministry, common practice in short-wave broadcasting transmitters at the time used currents of the order of $15 \mathrm{~A}$ in the transmitting antenna and 'after generous allowance (is made) for losses' this would yield a value at the ground 'of the order of a tenth of a millivolt per metre' $^{6}$; which indeed it would! Such field strengths were well within the capability of typical receiving equipment then in service and so he concluded that it would indeed be possible to detect an aircraft by means of the energy that it re-radiated from a suitable transmitter on the ground.

\section{THE EXPERIMENT}

The official reaction to the first draft of the memorandum, received on 12 February, was swift but its remarkable conclusions required demonstration before further action would be taken. This required funds and, displaying great faith in what, to some, was pure speculation, Air Marshall Sir Hugh Dowding made available the sum of $£ 10000$ to start experiments ${ }^{7}$. A test flight using an old metal-winged Heyford bomber, number K6902 (see Fig. 2) was arranged for 26 February. The intention was for the aircraft to fly a predetermined route between the BBC short-wave transmitter at Daventry, operating on a wavelength of $49.8 \mathrm{~m}$, and the town of Weedon just a few kilometres to the southeast. There, on the ground, was a small van that had been connected to a dipole antenna system slung between wooden poles, with a specially adapted radio receiver and the necessary cathode ray oscillograph, as oscilloscopes were known at that time, on which to view the results. The system was so adjusted that the amplitude of the signal received directly via the ground wave from Daventry would be nulled out and only the sky-wave component reflected from the aircraft would cause a deflection of the oscilloscope trace ${ }^{8}$.

The aircraft was flown by Flight Lieutenant R. S. Blucke RAF and the experiment proceeded exactly according to plan, with considerable variation occurring in the amplitude of the signal on the oscilloscope as the aircraft flew along its route and continuing for many minutes after it passed overhead. This was conclusive proof of Watson-Watt and Wilkins's theory and the Daventry experiment, as it has come to be known, was the undoubted precursor of the wartime radar system that not only won the war but ushered in the new era 


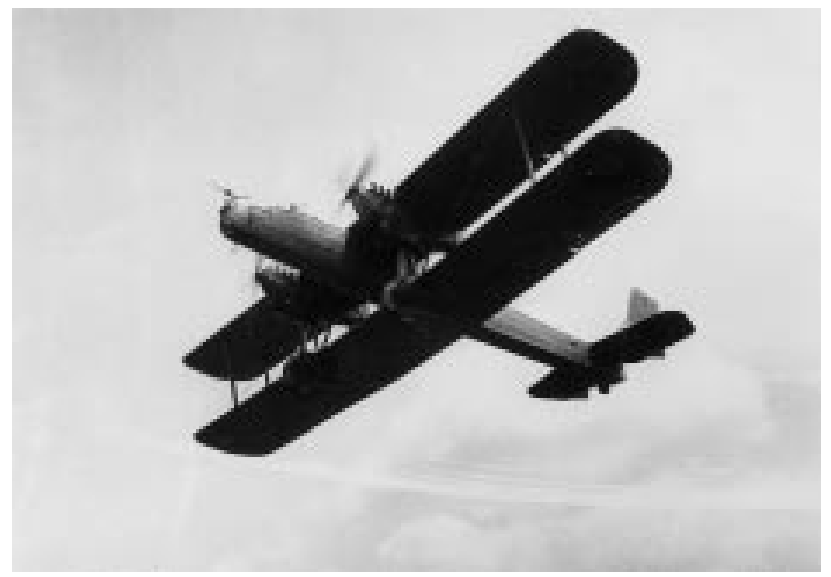

FIG. 2 The RAF Heyford bomber of the type that was the first radar target in England in February 1935 (with acknowledgement to The Trustees of the Imperial War Museum).

of radar and remote sensing and with them a whole host of new electronic technologies.

\section{CONCLUSION}

Watson-Watt's memorandum 'Detection and Location of Aircraft by Radio Methods' was presented to the Air Ministry on 27 February 1935. It was a truly remarkable document that essentially laid the foundations for the radar system that came into service four years later, was developed into air- and shipborne systems throughout the war and then, as technology advanced, became of fundamental importance in all manner of military and civilian roles in the post-war years. Radar is now so vital to the safety of life and limb in a world fast approaching its second millenium that it is now virtually taken for granted. However, it is well to remember how British radar all began with some simple calculations and the prescience of a remarkable man.

\section{REFERENCES}

[1] Burns, R. W., 'Air defence, some problems', Ch. 7, in Radar Development to 1945, Ed. R. W. Burns, Peter Peregrinus (1988)

[2] Jones, R. V., Most Secret War, Hamish Hamilton, p. 16 (1978)

[3] Ratcliffe, J. A., Biographical Memoirs of Fellows of The Royal Society, Robert Alexander Watson-Watt (1892-1973), 21, pp. 549-568 (1975)

[4] Jordan, E. C., Electromagnetic Waves and Radiating Systems, Prentice-Hall, p. 402 (1964)

[5] Ibid., p. 316

[6] Watson-Watt, R. A., Three Steps to Victory, Odhams Press, pp. 470-474 (1957)

[7] Clark, R. W., The Rise of the Boffins, Phoenix House, p. 35 (1962)

[8] Swords, S. S., Technical History of the Beginning of Radar, Peter Peregrinus, pp. 180-186 (1986) 


\section{ABSTRACTS - FRENCH, GERMAN, SPANISH}

Précurseurs du radar: le memorandum de Watson-Watt et l'expérience de Daventry

Dans cet article nous examinons le fameux memorandum non publié de 1935 dans lequel R. A. Watson-Watt a proposé les principes du radar. A partir des résultats numériques cités, nous montrons comment il arriva à ses conclusions en n'utilisant que de simple calculs. Les origines de cette importante technologie moderne sont à trouver dans une combinaison de prescience et de talents de base de l'ingénieur.

Vorläufer von Radar: das Watson-Watt Memorandum und das Daventry Experiment

In diesem Bericht untersuchen wir das berühmte, unveröffentlichte Memorandum von 1935, in dem R. A. Watson-Watt die Prinzipien des Radar vorschlug. Von den numerischen, von ihm angeführen Ergebnissen ausgehend zeigen wir, wie er auf seine Schlußfolgerungen kam, wobei er nur einfache Kalkulationen verwendete. Die Ursprünge einer wichtigen, modernen Technologie lassen sich in einer Kombination von Vorausschau und grundlegenden technischen Fähigkeiten finden.

Precursores del radar: El memorandum de Watson-Watt y el experimento de Daventry

En este artículo examinamos el famoso memorandum no publicado de 1935, en el cual R. A. Watson-Watt propone los principios del radar. Comenzando por los resultados numéricos que cita, mostramos como llega a sus conclusiones empleando nada mas que unos simples cálculos. Los orígenes de una moderna tecnología son encontrados en una combinación de preciencia y fundamentos de ingeniería básica.

ANNUAL INDEX

Printed copies of IJEEE will no longer incorporate a loose-leaf index. Instead, subscribers are invited to use the search facilities available with on-line versions of the journal. 